\title{
Malocclusion May Be Attributed to Variation among 10 Genes
}

\author{
Piper Dizak' ${ }^{1}$ John Burnheimer², Kathleen Deeley¹, Alexandre R. Vieira1 ${ }^{1}$ \\ ${ }^{1}$ Department of Oral Biology, School of Dental Medicine, University of Pittsburgh, Pittsburgh, USA \\ ${ }^{2}$ Department of Orthodontics and Dentofacial Orthopedics, School of Dental Medicine, University of Pittsburgh, Pittsburgh, USA \\ Email:pmd29@pitt.edu,jmb334@pitt.edu,kbd1@pitt.edu, arv11@pitt.edu
}

How to cite this paper: Dizak, P., Burnheimer, J., Deeley, K. and Vieira, A.R. (2021) Malocclusion May Be Attributed to Variation among 10 Genes. Open Journal of Stomatology, 11, 263-269.

https://doi.org/10.4236/ojst.2021.117023

Received: June 22, 2021

Accepted: July 20, 2021

Published: July 23, 2021

Copyright ( $) 2021$ by author(s) and Scientific Research Publishing Inc. This work is licensed under the Creative Commons Attribution International License (CC BY 4.0).

http://creativecommons.org/licenses/by/4.0/ (c) (i) Open Access

\begin{abstract}
Introduction: The goal of this study was to utilize physical characteristics instead of placing subjects in arbitrary diagnostic categories to test for associations with genetic variants. Methods: Forty-four single nucleotide polymorphisms were tested for association with specific cephalometric measurements in thirty-nine University of Pittsburgh Dental Registry and DNA Repository orthodontic subjects. Cephalometric measurements included an evaluation of FMA, a Wits appraisal, and a Steiner's ANB analysis. Genetic markers were genotyped using polymerase chain reaction and Taqman chemistry. Chi-square and Fischer's exact tests $(\alpha=0.05)$ were used in investigation of overrepresentation of marker alleles. Samples were divided into groups based upon having an FMA, Wits, or ANB measurement above or below the mean of the cohort studied. Secondary analysis was done for sex and ethnicity to determine their effect on FMA, Wits, or ANB. Results: An association between FMA measurements was discovered in the following genes: ACTN3, CASP4, ESR1, FGF13, KRT7, and PITX2. An association between Wits measurements was discovered in the following genes: ACTN2, BTBD11, CASP4, FGF3, and FGF10. No associations were found with ANB. Conclusions: Genetic markers in several genes at different loci may contribute to craniofacial deformities in humans. This approach of using physical measurements may be an advantage to placing patients in arbitrary diagnostic categories.
\end{abstract}

\section{Keywords}

Malocclusion, Multifactorial Inheritance, Genetic Association Studies, Linkage Disequilibrium, Genes

\section{Introduction}

Craniofacial abnormalities erupting during postnatal growth and development 
are often a result of both genetic and environmental influences [1]. Some of the most common types include cleft lip and/or cleft palate, craniosynostosis, and hemifacial microsomia. It has been documented that there is a link between certain craniofacial abnormalities and genetics [2] [3].

Cephalometric analyses can be used to measure vertical and horizontal relationships of craniofacial development, with the degree of departure from normal corresponding to the severity of the abnormality [4]. Three common cephalometric analyses include an evaluation of FMA (Frankfort mandibular angle), a Wits appraisal, and a Steiner's ANB analysis.

An FMA evaluation determines the skeletal vertical pattern of the patient, and is measured at the intersection of the Frankfort horizontal and mandibular plane [5]. FMA profiles include a normal vertical relationship at an angle of $25^{\circ} \pm 5^{\circ}$, an open vertical pattern at an angle greater than $30^{\circ}$, and a deep vertical relationship at an angle less than $20^{\circ}[6]$.

A Wits appraisal measures the linear maxillary and mandibular disharmony in the anteroposterior direction along the functional occlusal plane (FOP) [7]. A perpendicular line is dropped from the most anterior point on the maxilla (PtA) and the most anterior point on the mandible (PtB) to the (FOP) and the difference is measured. Class I Wits values range from $-1 \pm 2$ for males and $0 \pm 2$ for females. A Wits value less than -3 for males ( -2 for a females) would indicate Class III, whereas a Wits value greater than +1 for males ( +2 for females) would indicate Class II. Wits values differ depending on the sex of the patient. A limitation of this appraisal is that this measurement of jaw disharmony has no reference to external cranial morphology and is affected by the cant of the occlusal plane [7] [8].

In contrast to the linear measurement of Wits, the Steiner's ANB analysis measures the angular discrepancy between the maxilla and the mandible [9]. This analysis measures the angle (ANB) between PtA and PtB registered at $\mathrm{Na}$ sion. Steiner's ANB profiles include an ideal of $2^{\circ} \pm 2^{\circ}$ angle indicating a class I skeletal relationship, angles greater than $4^{\circ}$ indicating a class II skeletal relationship, and angles less than $0^{\circ}$ indicating a class III skeletal relationship. Limitations of this analysis include the position of the nasion, jaw rotations, and facial height [10].

The goal of this study was to use cephalometric measurements to identify genetic variants associated with craniofacial deformities among orthodontic patients. Preliminary work has shown associations when combining three cephalometric analyses to define the phenotype [11]. We aim to find genetic associations with these assessments analyzed individually.

\section{Materials and Methods}

The subjects in this study were patients treated in the Department of Orthodontics at the University of Pittsburgh School of Dental Medicine who had also volunteered to participate in the Dental Registry and DNA Repository project [12]. 
This project is approved by the University of Pittsburgh Institutional Review Board. All subjects provided written informed consent. Of the 95 patients that had been chosen for a previous study [11], 39 of those subjects were selected for this study. These subjects were chosen based upon their clinical and radiographic records and were included for having good quality images and measurements done and entered in the database. No individuals were excluded. The average age of participants was 17.8 years; 28 were female and 11 male; 20 were White, 13 were African American, two were Hispanic, and four were Asian. Table 1 displays all information used in this study. We followed the STROBE guidelines.

The mean of the cohort studied was calculated for each of the three measurements (FMA, Wits, and Steiner's), and subjects were placed into categories either above or below the mean for FMA, Wits, and Steiner's measurements. Significance from the mean was an arbitrary guide in comparing the difference in distribution of genotypes. Those found to be significant were further analyzed based upon sex and ethnic background, which were independently conducted and used to determine if the true significance was driven by either of these variables.

Forty-four single nucleotide polymorphisms were chosen for each subject based upon genes of interest previously found to be linked to prognathism [11]. These genetic markers were tested using end-point analysis of polymerase chain reactions using Taqman chemistry [13]. Chi-square and Fischer's exact tests $(\alpha=$ 0.05 ) were used in investigation of overrepresentation of marker alleles.

\section{Results}

An association between FMA measurements and markers in the genes of $A C T N 3$, CASP4, ESR1, FGF13, KRT7, and PITX2 was discovered (Table 2). Ethnicity was found to influence the associations with $E S R 1$ and $K R T 7$. Sex was not found to influence the association in any of the above genes.

An association between Wits measurements and markers in the genes of $A C T N 2, B T B D 11, C A S P 4, F G F 3$, and FGF10 was discovered (Table 2). Ethnicity was found to influence the association with $A C T N 2$. Sex was not found to influence the association in any of the above genes.

No associations with ANB measurements were detected.

\section{Discussion}

In this study, 44 single nucleotide polymorphisms were selected to uncover a common genetic variation in horizontal and vertical malocclusion. Our study provides evidence that a number of genes were associated with hyperdivergent facial patterns, or contribute to sagittal maxillomandibular discrepancies.

Estrogen (ESR1) is a key hormone for maintaining bone mass, maturation and skeletal growth. One function of the increase in serum estrogen during puberty would be to decrease the activity of osteoclasts, while increasing osteoblastic activity, which supports the importance of estrogen for jaw mass and growth [14]. 
Table 1. Summary of the subject's measurements $(n=39)$ used in this study.

\begin{tabular}{|c|c|c|c|c|c|c|}
\hline & Sex & Age (Years) & Ethnicity & FMA $\left({ }^{\circ}\right)$ & Wits & $\operatorname{ANB}\left({ }^{\circ}\right)$ \\
\hline 1 & M & 22 & Asian & 31.2 & -6.6 & 0.3 \\
\hline 2 & M & 17 & White & 22.2 & -12 & -8.1 \\
\hline 3 & $\mathrm{~F}$ & 23 & White & 24 & -17.5 & -10.1 \\
\hline 4 & $\mathrm{~F}$ & 19 & African American & 39.8 & -6.4 & 3.4 \\
\hline 5 & $\mathrm{~F}$ & 21 & African American & 26.8 & -4.5 & -1.9 \\
\hline 6 & $\mathrm{~F}$ & 20 & White & 23.3 & -6.8 & -4.9 \\
\hline 7 & $\mathrm{~F}$ & 18 & White & 28.8 & -6.5 & -1.9 \\
\hline 8 & M & 19 & White & 31.1 & -7.3 & -1.1 \\
\hline 9 & $\mathrm{~F}$ & 15 & African American & 19.3 & -3.4 & 2.5 \\
\hline 10 & $\mathrm{~F}$ & 14 & Hispanic & 31.6 & -6.2 & -2.7 \\
\hline 11 & $\mathrm{~F}$ & 22 & White & 22.6 & -15.7 & -6.6 \\
\hline 12 & $\mathrm{~F}$ & 12 & Asian & 28.8 & -5 & -2.3 \\
\hline 13 & $\mathrm{~F}$ & 20 & White & 26.9 & -7.6 & 0.7 \\
\hline 14 & M & 15 & White & 18.3 & -1.3 & 0.3 \\
\hline 15 & $\mathrm{~F}$ & 12 & Hispanic & 28.2 & -8.1 & 0.6 \\
\hline 16 & $\mathrm{~F}$ & 15 & White & 23.1 & -13.3 & -7.5 \\
\hline 17 & $\mathrm{~F}$ & 18 & White & 33 & -10.6 & -4.7 \\
\hline 18 & M & 18 & White & 23.4 & -7 & -1.9 \\
\hline 19 & $\mathrm{~F}$ & 11 & African American & 34.6 & -8.8 & 2.3 \\
\hline 20 & M & 11 & White & 19.3 & -7.8 & -4.4 \\
\hline 21 & $\mathrm{~F}$ & 16 & African American & 25.3 & -5 & -0.9 \\
\hline 22 & $\mathrm{~F}$ & 15 & White & 20.6 & -4.6 & -0.7 \\
\hline 23 & $\mathrm{~F}$ & 18 & White & 22.5 & -4.4 & -2.9 \\
\hline 24 & $\mathrm{~F}$ & 28 & African American & 20.8 & -5.9 & -1.0 \\
\hline 25 & $\mathrm{~F}$ & 13 & White & 20.9 & -5.4 & -0.9 \\
\hline 26 & $\mathrm{~F}$ & 23 & African American & 22.6 & -8.4 & -1.2 \\
\hline 27 & $\mathrm{~F}$ & 14 & White & 30.1 & -4.7 & -0.3 \\
\hline 28 & M & 24 & Asian & 34.7 & -4.1 & -3.4 \\
\hline 29 & $\mathrm{~F}$ & 18 & African American & 23.7 & -10 & -6 \\
\hline 30 & M & 19 & White & 33.2 & -7.8 & -1.4 \\
\hline 31 & $\mathrm{~F}$ & 15 & African American & 17.6 & -6.4 & 0.2 \\
\hline 32 & M & 12 & African American & 21.5 & -8.2 & -3.8 \\
\hline 33 & $\mathrm{~F}$ & 21 & African American & 23.3 & -4.3 & -4.8 \\
\hline 34 & $\mathrm{~F}$ & 15 & White & 32.7 & -10.7 & -2.7 \\
\hline 35 & M & 28 & White & 22 & -8.3 & -1.9 \\
\hline 36 & $\mathrm{~F}$ & 13 & African American & 18.5 & -12.8 & -4.1 \\
\hline 37 & $\mathrm{~F}$ & 13 & African American & 25.3 & -12.2 & -5.3 \\
\hline 38 & $\mathrm{~F}$ & 24 & White & 22.3 & -3.5 & -1.4 \\
\hline 39 & M & 24 & Asian & 14.9 & -4.2 & -3.6 \\
\hline Mean & - & 17.82 & - & 25.35 & -7.52 & -2.41 \\
\hline
\end{tabular}


Table 2. Summary of the association results.

\begin{tabular}{|c|c|c|c|c|c|}
\hline Gene & Marker & Test & $\begin{array}{c}\text { Associated } \\
\text { Allele/Genotype }\end{array}$ & $\mathrm{p}$-value & Trait \\
\hline$A C T N 3$ & rs1671064 & FMA & G vs. A & 0.003 & $\begin{array}{l}\text { G associated with tendency to have a higher-angle } \\
\text { FMA, A associated with tendency to have a } \\
\text { lower-angle FMA }\end{array}$ \\
\hline CASP4 & rs571407 & FMA & T vs. C & 0.04 & $\begin{array}{l}\text { T associated with tendency to have a higher-angle } \\
\text { FMA, C associated with tendency to have a } \\
\text { lower-angle FMA }\end{array}$ \\
\hline ESR1 & rs2077647 & FMA & CC vs. TT & 0.03 & $\begin{array}{l}\text { CC associated with tendency to have a higher-angle } \\
\text { FMA, TT associated with tendency to have a } \\
\text { lower-angle FMA }\end{array}$ \\
\hline$F G F 13$ & rs489895 & FMA & CT vs. TT & 0.03 & $\begin{array}{l}\text { Having at least one copy of } \mathrm{C} \text { associated with } \\
\text { tendency to have a higher-angle FMA, } \\
\text { TT associated with tendency to have a } \\
\text { lower-angle FMA }\end{array}$ \\
\hline$F G F 13$ & rs489895 & FMA & $\mathrm{C}$ vs. T & 0.04 & $\begin{array}{l}\text { C associated with tendency to have a higher-angle } \\
\text { FMA, T associated with tendency to have a } \\
\text { lower-angle FMA }\end{array}$ \\
\hline$K R T 7$ & rs7300317 & FMA & A vs. $G$ & 0.05 & $\begin{array}{l}\text { A associated with tendency to have a higher-angle } \\
\text { FMA, G associated with tendency to } \\
\text { have a lower-angle FMA }\end{array}$ \\
\hline PITX2 & rs2595110 & FMA & A vs. $G$ & 0.04 & $\begin{array}{l}\text { A associated with tendency to have a higher-angle } \\
\text { FMA, G associated with tendency to } \\
\text { have a lower-angle FMA }\end{array}$ \\
\hline ACTN2 & rs4659704 & Wits & CC vs. AC & 0.04 & $\begin{array}{l}\text { CC associated with tendency to have a less negative } \\
\text { Wits value, having at least one copy of A associated } \\
\text { with tendency to have a more negative Wits value }\end{array}$ \\
\hline BTBD11 & rs11113231 & Wits & GG vs. AA & 0.03 & $\begin{array}{l}\text { GG associated with tendency to have a less negative } \\
\text { Wits value, AA associated with tendency to have a } \\
\text { more negative Wits value }\end{array}$ \\
\hline CASP4 & rs571407 & Wits & T vs. C & 0.04 & $\begin{array}{l}\text { T associated with tendency to have a less negative Wits } \\
\text { value, } C \text { associated with tendency to have a more } \\
\text { negative Wits value }\end{array}$ \\
\hline$F G F 3$ & rs1893047 & Wits & AA vs. GG & 0.04 & $\begin{array}{l}\text { AA associated with tendency to have a less negative } \\
\text { Wits value, GG associated with tendency to have a } \\
\text { more negative Wits value }\end{array}$ \\
\hline$F G F 3$ & rs1893047 & Wits & A vs. $G$ & 0.02 & $\begin{array}{l}\text { A associated with tendency to have a less negative } \\
\text { Wits value, } G \text { associated with tendency to } \\
\text { have a more negative Wits value }\end{array}$ \\
\hline FGF10 & rs1448037 & Wits & T vs. C & 0.004 & $\begin{array}{l}\text { T associated with tendency to have a less negative } \\
\text { Wits value, } C \text { associated with tendency to } \\
\text { have a more negative Wits value }\end{array}$ \\
\hline
\end{tabular}

Notes: Higher FMA angles (greater than $30^{\circ}$ ) correlate to open-bite skeletal patterns, while lower FMA angles (fewer than $20^{\circ}$ ) correlate to deep-bite skeletal patterns. Less negative Wits values correlate to mandibular retrognatism, while more negative Wits values correlate to mandibular prognatism. Larger ANB angles (greater than $2^{\circ}$ ) correlate to the mandible being located behind the maxilla, while smaller ANB angles (fewer than $2^{\circ}$ ) correlate to the mandible being located ahead of the maxilla. 
This would be compatible with the functional matrix theory of Moss, where growth and the fundamental matrix are linked.

KRT7 encodes a protein which is a member of the keratin gene family. This protein is a type II cytokeratins consisting of basic or neutral proteins, arranged in pairs of heterotypic chains, coexpressed during differentiation of simple and stratified epithelial tissues. This type II cytokeratin is specifically expressed in the simple epithelia lining the cavities of the internal organs and in the gland ducts and blood vessels. KRT7 is clustered in a region of chromosome 12q12-q13. Its role in vertical jaw discrepancy remains unclear [15]. Similarly, the role of CASP4, $F G F 13, P I T X 2, B T B D 11, F G F 3$, and $F G F 10$ in post-natal craniofacial growth are not known.

ACTN2, located on the long arm of chromosome 1, is expressed in both slow type 1 and fast type 2 fibers. In skeletal muscle, alpha-Actinin- 2 crosslinks actin filaments. ACTN2 expression remains relatively constant irrespective of the changes in the ACTN3 genotype. However, ACTN3 R577X was associated with Class II and deepbite malocclusions [16]. As alpha-Actinin-2 and -3 are closely related isoforms, a compensatory effect may have occurred.

The small sample size of our study can be suggested as a limitation, however the exercise of characterizing the sample carefully aims to decrease heterogeneity and allow for more statistical power. Still, the associations reported here should be interpreted with caution and ideally independently replicated in other cohorts. Future studies will aim to predict postnatal craniofacial patterns and treatment outcomes from genomic profiles.

\section{Conclusion}

ACTN3, CASP4, ESR1, FGF13, KRT7, and PITX2 were associated with hyperdivergent skeletal pattern. ACTN2, BTBD11, CASP4, FGF3, and FGF10 were associated with sagittal maxillomandibular discrepancies. $F G F 10$ and $G H R$ were associated with ANB.

\section{Conflicts of Interest}

The authors declare no conflicts of interest regarding the publication of this paper.

\section{References}

[1] van der Linden, F.P.G.M. (1966) Genetic and Environmental Factors in Dentofacial Morphology. American Journal of Orthodontics, 52, 576-583. https://doi.org/10.1016/0002-9416(66)90138-2

[2] Wilkie, A.O.M. and Morriss-Kay, G.M. (2001) Genetics of Craniofacial Development and Malformation. Nature Reviews Genetics, 2, 458-468. https://doi.org/10.1038/35076601

[3] Harris, J.E. (1975) Genetic Factors in the Growth of the Head. Inheritance of the Craniofacial Complex and Malocclusion. Dental Clinics of North America, 19, 151 160. 
[4] Keeling, S.D., Riolo, M.L., Martin, R.E. and Ten Have, T.R. (1989) A Multivariate Approach to Analyzing the Relation between Occlusion and Craniofacial Morphology. American Journal of Orthodontics and Dentofacial Orthopedics, 95, 297-305. https://doi.org/10.1016/0889-5406(89)90162-5

[5] Johnson, E.L. (1950) The Frankfort-Mandibular Plane Angle and the Facial Pattern. American Journal of Orthodontics and Dentofacial Orthopedics, 36, 516-533. https://doi.org/10.1016/0002-9416(50)90064-9

[6] Tweed, C.H. (1953) Evolutionary Trends in Orthodontics, Past, Present, Future. American Journal of Orthodontics, 39, 81-108. https://doi.org/10.1016/0002-9416(53)90014-1

[7] Jacobson, A. (1976) Application of the "Wits" Appraisal. American Journal of Orthodontics, 70, 179-189. https://doi.org/10.1016/S0002-9416(76)90318-3

[8] Nanda, R.S. (2004) Reappraising “Wits". American Journal of Orthodontics and Dentofacial Orthopedics, 125, A18. https://doi.org/10.1016/j.ajodo.2003.12.012

[9] Steiner, C.C. (1953) Cephalometrics for You and Me. American Journal of Orthodontics, 39, 729-755. https://doi.org/10.1016/0002-9416(53)90082-7

[10] Taylor, C.M. (1969) Changes in the Relationship of Nasion, Point A, and Point B and the Effect upon ANB. American Journal of Orthodontics, 56, 143-163. https://doi.org/10.1016/0002-9416(69)90231-0

[11] Tassopoulou-Fishell, M., Deeley, K., Harvey, E.M., Sciote, J. and Vieira, A.R. (2012) Genetic Variation in Myosin $1 \mathrm{H}$ Contributes to Mandibular Prognathism. American Journal of Orthodontics and Dentofacial Orthopedics, 141, 51-59. https://doi.org/10.1016/j.ajodo.2011.06.033

[12] Vieira, A.R., Hilands, K.M. and Braun, T.W. (2015) Saving More Teeth-A Case for Personalized Care. Journal of Personalized Medicine, 5, 30-35.

https://doi.org/10.3390/jpm5010030

[13] Ranade, K., Chang, M.S., Ting, C.T., Pei, D., Hsiao, C.F., Olivier, M., et al. (2001) High-Throughput Genotyping with Single Nucleotide Polymorphisms. Genome Research, 11, 1262-1268.

[14] Bobek, J., Oralava, V., Lesot, H., Kratochvilova, A., Doubek, J. and Matalova, E. (2020) Onset of Calciotropic Receptors during the Initiation of Mandibular/Alveolar Bone Formation. Annals of Anatomy, 227, Article ID: 151427. https://doi.org/10.1016/j.aanat.2019.151427

[15] Doraczynska-Kowalik, A., Nelke, K.H., Pawlak, W., Sasiadek, M.M. and Gerber, H. (2017) Genetic Factors Involved in Mandibular Prognathism. Journal of Craniofacial Surgery, 28, e422-e431. https://doi.org/10.1097/SCS.0000000000003627

[16] Zebrick, B., Teeramongkolgul, T., Nicot, R., Horton, M.J., Raoul, G., Ferri, J., Vieira, A.R. and Sciote, J.J. (2014) ACTN3 R577X Genotypes Associate with Class II and Deepbite Malocclusions. American Journal of Orthodontics and Dentofacial Orthopedics, 146, 603-611. https://doi.org/10.1016/j.ajodo.2014.07.021 